\title{
Peningkatan Network Lifetime Menggunakan Cluster Based Pada Wireless Sensor Network
}

\author{
Muhammad Hibrian ${ }^{1}$, Wardi $^{2}$, Agussalim $^{3}$ \\ 1 Magister Sistem Komputer, STMIK Handayani, Jl. Adhyaksa Baru No. 1 Makassar, Indonesia \\ 2 Teknik Elektro, Universitas Hasanuddin, Jl Perintis Kemerdekaan, Makassar, Indonesia \\ 3. Sistem Informasi, Universitas Pembangunan Nasional "Veteran” Jawa Timur, Jl. Medokan Ayu No. 1, Surabaya, Indonesia
}

\section{ARTICLE INFORMATION}

Received: January $26^{\text {th }}, 2020$

Revised: March $8^{\text {th }}, 2020$

Available online: March $30^{\text {th }}, 2020$

\section{KEYWORDS}

WSN, Routing, Network Lifetime, LEACH

\section{CORRESPONDENCE}

Phone: +6285696128584

E-mail: muhammadhibrian@gmail.com

\section{A B S S T R A C $\mathbf{C}$}

This series of research activities are in the form of a routing simulation using the LEACH protocol as a cluster-based mechanism method that can improve Network Lifetime in the Wireless Sensor Network protocol, using the Network Simulator 2 application device that describes data transmission, remaining nodes, and energy used. Determination of the performance and power consumption of the wireless sensor network by testing scenario one to scenario five due to the influence of the cluster to be applied, such as scenario 1 using 1 cluster $(\mathrm{C} 1)$ consumes an average of the energy of 0.155 joules and the data sent or obtained is 72,848 bytes. Barriers or disruptions to the cluster head affect the performance of LEACH, so there is a need for criteria or conditions to determine which nodes should be used as cluster head.

\section{PENDAHULUAN}

Untuk beberapa skenario aplikasi lainnya, jaringan dan aktuator dibangun menggunakan teknologi jaringan kabel. Bagi banyak jenis aplikasi lainnya, penggunaan kawat menjadi sulit atau tidak bisa diterapkan. Wiring/ pengkabelan mahal dan pemeliharaannya juga susah, tidak bisa mobile, dan kabel dapat mencegah sensor atau aktuator menjadi dekat dengan fenomena yang diamati, padahal mereka seharusnya berfungsi untuk mengontrol. Oleh karena itu komunikasi nirkabel antara perangkat tersebut menjadi kebutuhan yang tak terelakan [1]. Contohnya seperti penerapan teknologi Wireless Sensor Network (WSN).

Wireless sensor network (WSN) memakai daya baterai sebagai sumber daya untuk menghidupkan perangkat node-nodenya. salah satu masalah atau tantangan dalam pengimplementasian WSN yang utama pada sensor nirkabel adalah memiliki sumber daya energi yang terbatas, sumber energi berupa daya baterai diperlukan untuk menghidupkan perangkat wireless sensor network (WSN) karena proses pergantian baterai atau pemasangan sumber energi lainnya tidak memungkinkan yang dipengaruhi medan atau alam yang ekstrim, sehingga masalah tersebut dapat mempengaruhi kinerja dari sensor. Sumber daya yang digunakan akan habis atau mati, dikarenakan pemakaian secara terus-menerus maka dibutuhkan sebuah penerapan algoritma atau protokol untuk mengefisienkan penggunaan baterai di dalam WSN.

Masa hidup (lifetime) dalam teknologi WSN perlu dipertimbangkan lagi untuk ditingkatkan agar manfaat WSN dapat dirasakan lebih lama. Penelitian terkini dalam meningkatkan masa hidup WSN cenderung dilakukan dengan mengembangkan protokol-protokol energy aware routing yang melibatkan agregasi data, clustering,dan scheduling yang diharapkan mampu menghemat sumber daya energi dari sensor node [3] 
Penerapan teknik clustering dengan menggunakan salah satu teknik protokol yang ada pada WSN yakni dengan menerapkan protokol LEACH (Low Energy Adaptive Cluster Hierarcy) yang nantinya dapat menganalisis kinerja dan konsumsi daya WSN yang dapat meningkatkan atau mengoptimalkan masa hidup jaringan.

\section{Wireless Sensor Network}

Sensor-sensor yang menjalankan fungsi secara terintegrasi antara sensor yang satu dan sensor lainnya membentuk sebuah pola dan tujuan tertentu seperti mengirim, menerima, serta memproses data disekitarnya menuju base station sehingga membentuk jaringan dengan menggunakan perantara udara sebagai media transmisinya disebut Wireless Sensor Network (WSN), seperti dapat dilihat pada [2]

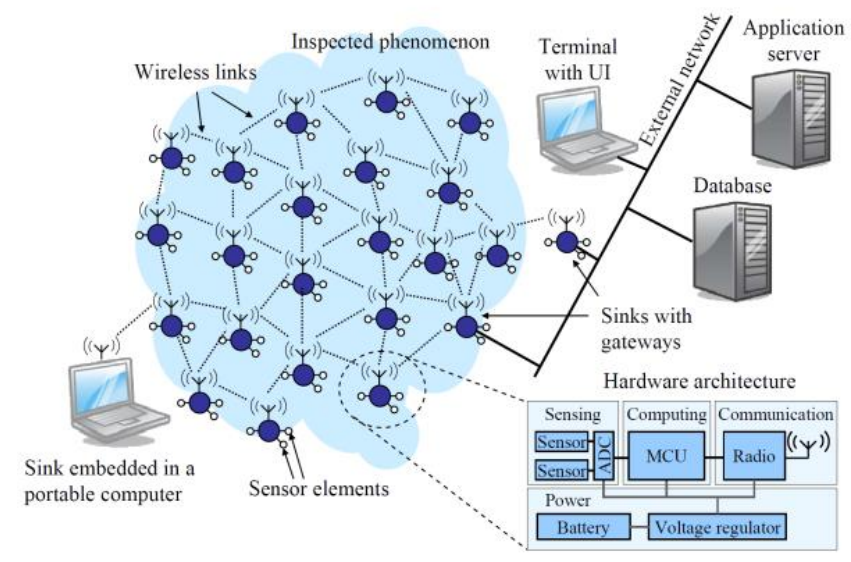

Gambar 1. Topologi Wireless Sensor Network dan Arsitektur Node [2]

WSN merupakan kesatuan perangkat sensor yang mengumpulkan data dari alam dan mengirimkan kepada administrator. Secara umum WSN terdiri dari dua komponen yaitu node sensor dan sink. Node sensor merupakan komponen kesatuan dari jejaring yang dapat menghasilkan informasi, biasanya merupakan sebuah sensor atau juga sebuah aktuator yang menghasilkan feedback pada keseluruhan operasi.

Sink merupakan kesatuan sensor yang dapat melakukan pengolahan informasi dari setiap node sensor. Keunggulan dari WSN ini adalah mempunyai daya jangkauan yang lebih luas akurat dan juga harga yang lebih murah. Ini dikarenakan kemajuan di bidang desain, konsep dan pemilihan material sehingga diperoleh sensor yang lebih murah, minimalis dan ringan. Simulasi ini dilakukan guna untuk memperoleh penjelasan, deskripsi dan prediksi suatu sistem WSN yang akan direalisasikan kedalam dunia nyata dalam skala besar guna mengurangi kegagalan dalam realisasi tersebut maka harus dilakukan simulasi terlebih dahulu [3].

\section{Network Lifetime}

Network Life Time dapat diartikan dengan masa hidup suatu jaringan sensor, tetapi seperti yang telah dijelaskan pada penelitian [3] yakni Network Lifetime atau masa hidup sebuah jaringan sensor memiliki berbagai definisi. Masing- masing definisi memiliki batasan dan belum ada yang bisa diterapkan pada semua kriteria jaringan. Penelitian [4] menyatakan bahwa network lifetime adalah waktu hingga cluster head $(\mathrm{CH})$ yang pertama mati. Definisi ini menjadi tidak relevan ketika protokol clustering mulai mampu menangani perubahan topologi dengan mengganti cluster head $(\mathrm{CH})$.

Network lifetime atau masa hidup suatu jaringan sensor memiliki berbagai definisi. Masing-masing definisi memiliki batasan dan belum ada yang bisa diterapkan pada semua kriteria jaringan. Penelitian awal yang merumuskan network lifetime sebagai rentang waktu sejak dimulainya transmisi data yang pertama hingga node terakhir mati dikemukakan oleh [5]. Namun pada kenyataannya, sebuah jaringan sensor sudah tidak bisa mengirim data pemindaian, meskipun belum semua node mati.Definisi berikutnya yang lebih realistis dikemukakan seiring dengan berkembangnya metode routing berbasis cluster (klaster). paper [6] menyatakan bahwa network lifetime adalah waktu hingga cluster head $(\mathrm{CH})$ yang pertama mati. Definisi ini menjadi tidak relevan ketika protokol clustering mulai mampu menangani perubahan topologi dengan mengganti CHnya. Banyaknya Definisi dari network lifetime peneliti kali ini mengacu pada pernyataan yang dikemukakan oleh [3] didefinisikan sebagai waktu sensor node yang pertama mengalami kehabisan energi untuk beroperasi.

\section{LEACH (Low Energy Adaptive Cluster Hierarcy)}

Teknik clustering pada WSN umumnya digunakan dengan tujuan penghematan sumber daya energy. Salah satu protokol clustering yang popular adalah LEACH. LEACH (Low-Energy Adaptive Clustering Hierarchy) adalah sebuah protokol routing yang bertujuan untuk meningkatkan konservasi energi [6]

Penelitian LEACH telah diteliti sebelumnya oleh [7] dalam penelitiannya dijelaskan LEACH merupakan protokol routing yang membentuk cluster (klaster) dari kumpulan node sensor berdasarkan kekuatan sinyal yang diterima. Algoritma dimulai dengan pemilihan suatu node sebagai $\mathrm{CH}$ lalu dengan algoritma clustering memilih node non- $\mathrm{CH}$ sebagai anggota sehingga membentuk klaster seperti yang terlihat pada Gambar 2. Mekanisme ini menghemat energi karena hanya $\mathrm{CH}$ yang melakukan transmisi data ke Base Station, sedangkan tiap node sensor cukup mengirim data ke $\mathrm{CH}$ masing-masing. akibatnya konsumsi energi berkurang, sehingga Lifetime jaringan sensor menjadi maksimal.

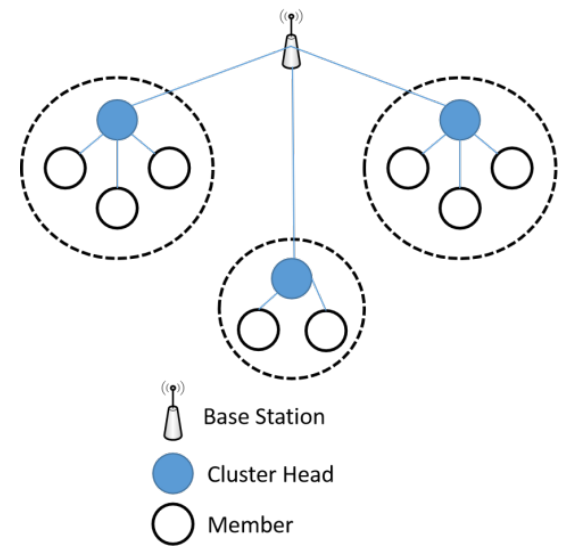

Gambar 2 Beberapa sensor node yang Dibagi Menjadi Beberapa Cluster dan Memiliki CH

Menurut paper [7] bahwa pada awalnya node-node tersebar dalam jumlah besar pada suatu area dan proses pengiriman data masih terpusat pada Base Station. Namun dengan adanya algoritma LEACH, node-node tersebut dikelompokkan dalam beberapa klaster pada satu jaringan. Masing-masing klaster memiliki sebuah $\mathrm{CH}$ yang bertugas untuk mengkoordinasi 
pengiriman data dari node sensor ke Base Station. LEACH memiliki fitur-fitur sebagai berikut:

1. Data fusion, yaitu penggabungan data sehingga mengurangi disipasi energi dan menambah lifetime jaringan.

2. Adaptive, yaitu mudah untuk menyesuaikan diri saat pembentukan formasi klaster

3. Local compression, yaitu mengkompresi data agar ukuran data yang dikirim ke Base Station lebih kecil

4. Randomization rotation, yaitu perputaran kedudukan $\mathrm{CH}$ secara acak.

5. Self-Organizing, yaitu tiap node sensor memiliki sikap pengambilan keputusan sendiri untuk menjadi $\mathrm{CH}$.

\section{METODE}

Simulasi ini menggunakan NS-2 (network simulator) versi 2 sebagai media simulatornya dengan memodifikasi protokol LEACH yang meliputi penambahan luas area, penambahan jumlah node serta memodifikasi jumlah klaster yang telah diteliti oleh beberapa penelitian sebelumnya.

Simulator jaringan ns-2 adalah simulator jaringan berlisensi open source yang mendukung banyak aplikasi, protokol-protokol, dan model-model trafik jaringan yang dirancang khusus untuk penelitian komunikasi data dan jaringan. Simulator ns-2 bekerja di atas penggunaan 2 bahasa pemrograman yaitu (1) $\mathrm{C}++$ yang digunakan untuk mendefinisikan mekanisme internal (back-end) dari objek simulasi serta menangani paket data, dan (2) bahasa objectoriented tool command language (OTcl) sebagai interpreter yang digunakan untuk menjalankan simulasi pada modul yang telah disediakan oleh ns-2, mengkonfigurasi berbagai parameter, melakukan penjadwalan event diskret, serta menjalankan script perintah dari pengguna. Bahasa $\mathrm{C}++$ dan OTcl dihubungkan satu sama lain menggunakan TclCL. Arsitektur dasar simulator jaringan ns-2 dapat dilihat pada Gambar 3

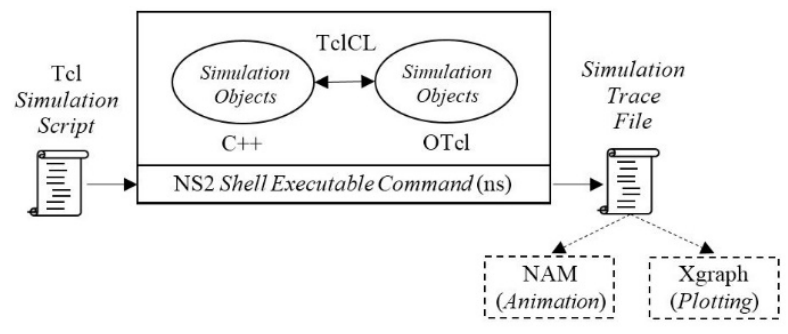

Gambar 3 Arsitektur simulator jaringan ns-2 [8]

Penelitian ini merupakan perkembangan dari paper [8] yang menjelaskan bahwa LEACH berjalan dalam sepanjang jumlah round yang dapat ditempuh sampai dengan energi yang ditetapkan habis terpakai. Setiap kali LEACH ingin menginisiasi pembentukan klaster terdapat 2 fase aktivitas yang dilewati yaitu set up phase dan steady phase

$$
T(n)=\left\{\begin{array}{l}
\frac{C P}{1-C P[r * \bmod (} \\
0,
\end{array}\right.
$$

Set up phase: Menurut [9] selama set up phase $\mathrm{CH}$ dipilih secara acak di antara node-node yang berada di dalam satu klaster. Pada awalnya, setiap node membangkitkan suatu nilai acak yang berada pada rentang 0 sampai 1 . Jika nilai tersebut kurang dari threshold atau $T(n)$ yang ditetapkan, maka node tersebut dipilih sebagai $\mathrm{CH}$ untuk suatu round. Pemilihan ini juga melibatkan history dari daftar node-node yang telah menjadi $\mathrm{CH}$ menurut [10]. T(n) dapat dihitung menggunakan Persamaan 1 [11]. Cluster percentage $(\mathrm{CP})$ adalah presentase dari jumlah klaster di dalam jaringan, $r$ adalah jumlah dari round pemilihan, $(r \bmod 1 / \mathrm{CP})$ adalah jumlah node yang telah terpilih sebagai $\mathrm{CH}$ di dalam round ke- $r$, dan $G$ adalah sekumpulan node yang belum terpilih sebagai $\mathrm{CH}$ pada round ke $r$. Begitu para $\mathrm{CH}$ terpilih, para $\mathrm{CH}$ akan menyebarluaskan pesan advertisement. Berdasarkan dari kekuatan sinyal yang diterima, setiap node yang bukan $\mathrm{CH}$ akan memilih CH-nya, dalam kasus ini node dapat mendengar lebih dari satu pesan broadcast pada round tersebut. Setiap node yang bukan $\mathrm{CH}$ akan mengirim kembali pesan request untuk bergabung, berisikan ID node tersebut ke $\mathrm{CH}$-nya yang dipilih menggunakan carrier sense multiple access (CSMA) yang juga berfungsi untuk menangani collision. Setelah tahapan set up, setiap $\mathrm{CH}$ akan mengetahui setiap anggota klaster beserta ID-nya masing-masing [12]. Flowchart dari algoritme pembentukan klaster pada protokol LEACH.

Steady state phase: Setelah klaster-klaster terbentuk, $\mathrm{CH}$ mengalokasikan penjadwalan TDMA-nya ke node-node anggota klasternya. Berdasarkan dari penjadwalan tersebut setiap anggota node akan mengirimkan data hasil sensing-nya ke $\mathrm{CH}$ masingmasing. Begitu $\mathrm{CH}$ mengumpulkan semua data dari node-node anggotanya, $\mathrm{CH}$ akan mengirimkan data yang telah terkumpul tersebut bersamaan dengan data yang dimilikinya sendiri ke BS [13]. Durasi waktu dari tahapan steady state lebih lama daripada tahapan set up. Setelah sekian waktu tertentu, jaringan kembali memasuki tahapan set up dari round berikutnya. $\mathrm{CH}$ akan terpilih lagi untuk membentuk klaster baru. Dengan demikian, lama waktu hidup jaringan dapat diestimasi berdasarkan jumlah round yang berhasil dicapai. Time-line operasi pada protokol routing LEACH yang terdiri atas fase set up dan steady state.

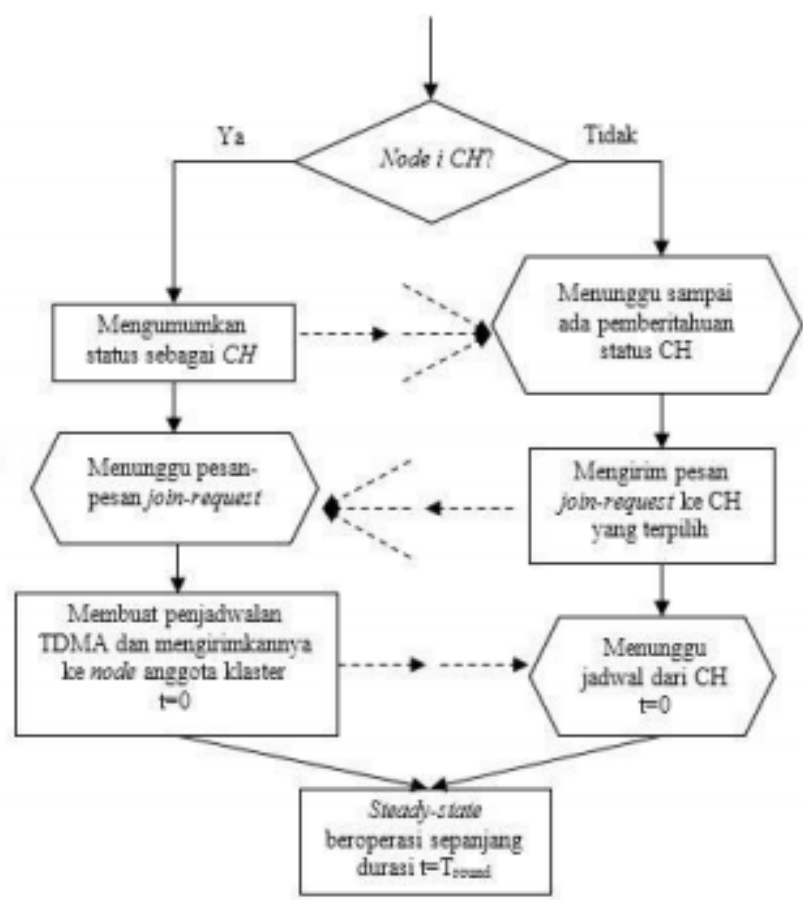

Gambar 4 Algoritma pembentukan klaster LEACH [6]

Skenario dalam penelitian ini dengan melaksanakan pengujian menggunakan skenario 1 sampai skenario 5 disertai beberapa parameter atau variable yang diubah-ubah agar mendapatkan klaster yang efisien atau optimal dengan cara menggunakan simulasi ns-2, Dalam penelitian ini telah dilakukan pengulangan sebanyak 4 kali dan memiliki hasil yang sama persis bahwa nilai yang dihasilkan pada setiap skenario mendapatkan jumlah klaster yang optimum seperti pada skenario ke-3 optimasi network lifetime dengan memakai $\mathrm{CH}$ terbaik yaitu sebanyak 5 klaster. Beberapa node yang tersebar luas yang didasari pada code extentions MIT u-AMPS dan parameter-parameternya tersebar di koordinat-koordint sebagai berikut : 
Tabel 1 Skenario banyaknya node dan klaster yang diterapkan

\begin{tabular}{|lccccc|}
\hline $\begin{array}{c}\text { Node / } \\
\text { Cluster }\end{array}$ & $\begin{array}{c}\mathbf{1 0} \\
\text { (Skena } \\
\text { rio 1) }\end{array}$ & $\begin{array}{c}\text { 50 } \\
\text { (Skena } \\
\text { rio 2) }\end{array}$ & $\begin{array}{c}\text { 100 } \\
\text { (Skena } \\
\text { rio 3) }\end{array}$ & $\begin{array}{c}\text { 150 } \\
\text { (Skena } \\
\text { rio 4) }\end{array}$ & $\begin{array}{c}\text { 200 } \\
\text { (Skena } \\
\text { rio 5) }\end{array}$ \\
\hline C1 & $\sqrt{ }$ & $\sqrt{ }$ & $\sqrt{ }$ & $\sqrt{ }$ & $\sqrt{ }$ \\
C2 & $\sqrt{ }$ & $\sqrt{ }$ & $\sqrt{ }$ & $\sqrt{ }$ & $\sqrt{ }$ \\
C3 & $\sqrt{ }$ & $\sqrt{ }$ & $\sqrt{ }$ & $\sqrt{ }$ & $\sqrt{ }$ \\
C4 & $\sqrt{ }$ & $\sqrt{ }$ & $\sqrt{ }$ & $\sqrt{ }$ & $\sqrt{ }$ \\
C5 & $\sqrt{ }$ & $\sqrt{ }$ & $\sqrt{ }$ & $\sqrt{ }$ & $\sqrt{ }$ \\
C6 & $\sqrt{ }$ & $\sqrt{ }$ & $\sqrt{ }$ & $\sqrt{ }$ & $\sqrt{ }$ \\
C7 & $\sqrt{ }$ & $\sqrt{ }$ & $\sqrt{ }$ & $\sqrt{ }$ & $\sqrt{ }$ \\
C8 & $\sqrt{ }$ & $\sqrt{ }$ & $\sqrt{ }$ & $\sqrt{ }$ & $\sqrt{ }$ \\
C9 & $\sqrt{ }$ & $\sqrt{ }$ & $\sqrt{ }$ & $\sqrt{ }$ & $\sqrt{ }$ \\
C10 & $\sqrt{ }$ & $\sqrt{ }$ & $\sqrt{ }$ & $\sqrt{ }$ & $\sqrt{ }$ \\
\hline
\end{tabular}

Setiap Node yang diuji terdiri dari Node 10 (Skenario 1), 50 (Skenario 2), 100 (Skenario 3), 150 (Skenario 4), dan 200 (Skenario 5) yang dapat dibagi menjadi beberapa klaster dari 1 klaster sampai dengan 10 klaster yakni C1, C2, C3, C4, C5, C6, C7, C8, C9 dan C10, setiap klaster dapat di uji pada setiap node dari skenario 1 sampai skenario 5 sehingga mendapatkan network lifetime yang optimal yaitu mencari nilai AED (average energy dissipated) dan ADR (average data received).

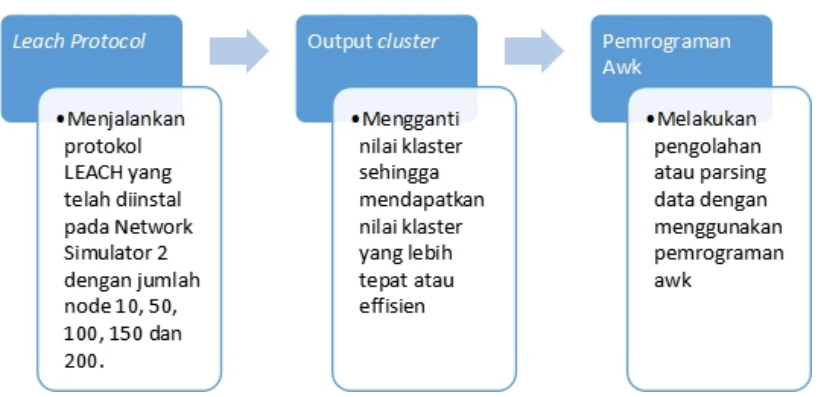

Gambar 4. Skema pengujian protocol LEACH

\section{HASIL DAN PEMBAHASAN}

Pada Tahap ini dilakukan simulasi sesuai skenario dan parameter yang telah dijelaskan sebelumnya yakni setiap node dan setiap klasternya dapat dihasilkan. Dalam tahapan ini peneliti mencari nilai AED (average energy dissipated) dan ADR (average data received), menurut heinzelman Hal ini dilakukan untuk melihat atau menghitung nilai rata-rata energi yang dihabiskan per satu round untuk setiap simulasi. Total energi yang dipakai seluruh jaringan di akhir simulasi dibagi dengan banyaknya round yang berhasil dicapai selama durasi simulasi menghasilkan nilai average energy dissipated (AED) atau nilai rata-rata energi yang dihabiskan per round sedangkan average data received (ADR) yaitu total data saat simulasi selesai dibagi dengan jumlah round.

\subsubsection{Sensor berjumlah 10 Node}

Pada pengujian ini kami menguji 10 node sensor, hasil pengujian Menunjukkan bahwa AED (average energy dissipated) dan ADR (average data received) klaster yang paling hemat menggunakan energi dan data yang banyak terkirim ke base station adalah menggunakan 1 klaster (C1) saja dikarenakan rata-rata penggunaan energi adalah sebesar 0.15 joule serta rata-rata data yang terkirim atau peroleh sebanyak 72,84 bytes.

Tabel 2 Total Energi dan Total Data yang menggunakan 10 node

\begin{tabular}{|ccccc|}
\hline 10 & Total & Total & AED per \\
Nodes & Round & Energi & $\begin{array}{c}\text { ADR per } \\
\text { Data }\end{array}$ & $\begin{array}{c}\text { Round } \\
\text { Round }\end{array}$ \\
\hline
\end{tabular}

\begin{tabular}{lrrrrr|}
\hline C1 & 129,2 & 20 & 9412 & 0,15 & 72,84 \\
C2 & 110,7 & 19,73 & 2952 & 0,17 & 26,66 \\
C3 & 114,4 & 19,49 & 5780 & 0,17 & 50,52 \\
C4 & 109 & 19,39 & 4383 & 0,17 & 40,21 \\
C5 & 81,9 & 19,30 & 2593 & 0,23 & 31,66 \\
C6 & 69,3 & 18,29 & 1723 & 0,26 & 24,86 \\
C7 & 50,9 & 18,09 & 492 & 0,35 & 9,66 \\
C8 & 48,3 & 17,88 & 556 & 0,37 & 11,51 \\
C9 & 40,3 & 17,46 & 332 & 0,43 & 8,23 \\
C10 & 38,8 & 19,027 & 0 & 0,49 & 0 \\
\hline
\end{tabular}

\subsubsection{Sensor berjumlah 50 Node}

Pada pengujian ini kami menguji 50 node sensor, hasil pengujian menunjukkan bahwa AED (average energy dissipated) atau energi rata-rata yang dilewati setiap round paling optimal adalah $\mathrm{C} 2$ atau menggunakan 2 klaster yakni menghasilkan 0.27 joule yang menunjukan ADR (average data received) atau data yang terkirim adalah menggunakan 2 klaster juga dengan nilai sebesar 107,41 bytes.

Tabel 3 Total Energi dan Total Data yang menggunakan 50 node

\begin{tabular}{|c|c|c|c|c|c|}
\hline $\begin{array}{c}50 \\
\text { Nodes }\end{array}$ & Round & $\begin{array}{c}\text { Total } \\
\text { Energi }\end{array}$ & Data & $\begin{array}{c}\text { AED per } \\
\text { Round }\end{array}$ & $\begin{array}{l}\text { ADR per } \\
\text { Round }\end{array}$ \\
\hline $\mathrm{C} 1$ & 123,4 & 100 & 11610 & 0,81 & 94,08 \\
\hline $\mathrm{C} 2$ & 359 & 99,83 & 38563 & 0,278 & 107,41 \\
\hline $\mathrm{C} 3$ & 218,4 & 99,45 & 19482 & 0,45 & 89,20 \\
\hline $\mathrm{C} 4$ & 262,7 & 98,68 & 19391 & 0,37 & 73,81 \\
\hline $\mathrm{C} 5$ & 260,7 & 99,22 & 16277 & 0,38 & 62,43 \\
\hline C6 & 222,4 & 99,78 & 16763 & 0,44 & 75,37 \\
\hline C7 & 143,3 & 96,77 & 9928 & 0,67 & 69,28 \\
\hline $\mathrm{C} 8$ & 135,4 & 96,71 & 9585 & 0,71 & 70,79 \\
\hline C9 & 102,1 & 96,39 & 4537 & 0,94 & 44,43 \\
\hline $\mathrm{C} 10$ & 96,7 & 99,41 & 2932 & 1,02 & 30,32 \\
\hline
\end{tabular}

4.2.3 Sensor berjumlah 100 Node

Pada pengujian ini kami menguji 100 node sensor, hasil pengujian menunjukkan jumlah rata-rata penggunaan energi per round yang paling hemat atau efisien adalah menggunakan 5 klaster (C5) yakni sebesar 0,37 joule. Pada Tabel 4 menunjukan juga bahwa penggunaan 5 klaster (C5) dengan rata-rata data per round atau ADR (average data received) berjumlah 103,51 bytes.

Tabel 4 Total Energi dan Total Data yang menggunakan 100 node

\begin{tabular}{|lrrrrr|}
\hline $\begin{array}{c}\text { 100 } \\
\text { Nodes }\end{array}$ & Round & \multicolumn{1}{c}{$\begin{array}{c}\text { Total } \\
\text { Energi }\end{array}$} & \multicolumn{1}{c}{ Data } & \multicolumn{1}{c|}{$\begin{array}{c}\text { AED per } \\
\text { Round }\end{array}$} & $\begin{array}{c}\text { ADR per } \\
\text { Round }\end{array}$ \\
\hline C1 & 64,6 & 200 & 2698 & 3,09 & 41,76 \\
C2 & 513 & 199,8651400 & 0,38 & 100,19 \\
C3 & 434,7 & 199,8448492 & 0,45 & 111,55 \\
C4 & 382,3 & 199,1435480 & 0,52 & 92,80 \\
C5 & 529,8 & 199,8054841 & 0,37 & 103,51 \\
C6 & 305,3 & 198,0825963 & 0,64 & 85,04 \\
\hline
\end{tabular}




\begin{tabular}{lllll|}
\hline C7 & 312,2 & 196,7826168 & 0,63 & 83,81 \\
C8 & 145,5 & 198,2210105 & 1,36 & 69,45 \\
C9 & 187,2 & $199,36 \quad 7528$ & 1,06 & 40,21 \\
C10 & 186,3 & 196,9011715 & 1,05 & 62,88 \\
\hline
\end{tabular}

\subsubsection{Sensor berjumlah 150 Node}

Pada pengujian ini kami menguji 150 node sensor, hasil pengujian menunjukkan jumlah rata-rata penggunaan energi per round yang paling hemat atau efisien adalah menggunakan 3 klaster (C3) 0,30 joule. Pada Tabel 5 menunjukan juga bahwa C3 dengan rata-rata data per round atau ADR (average data received) berjumlah 109,77 bytes.

Tabel 5 Total Energi dan Total Data yang menggunakan 150 node

\begin{tabular}{|c|c|c|c|c|c|}
\hline \begin{tabular}{|c|}
150 \\
Nodes \\
\end{tabular} & Round & Energi & Data & $\begin{array}{c}\text { AED per } \\
\text { Round }\end{array}$ & $\begin{array}{c}\text { ADR per } \\
\text { Round }\end{array}$ \\
\hline $\mathrm{C} 1$ & 105,5 & 300 & 10950 & 2,84 & 103,79 \\
\hline C2 & 171,2 & 300 & 16091 & 1,75 & 93,98 \\
\hline C3 & 996,1 & 299,89 & 109344 & 0,30 & 109,77 \\
\hline C4 & 525,6 & 299,61 & 49055 & 0,57 & 93,33 \\
\hline C5 & 756,1 & 298,39 & 76836 & 0,39 & 101,62 \\
\hline C6 & 512,1 & 299,05 & 44337 & 0,58 & 86,57 \\
\hline C7 & 475,5 & 298,62 & 37814 & 0,62 & 79,52 \\
\hline C8 & 237,4 & 299,18 & 15761 & 1,26 & 66,39 \\
\hline C9 & 264,5 & 296,42 & 21545 & 1,12 & 81,45 \\
\hline $\mathrm{C} 10$ & 272,5 & 298,09 & 20355 & 1,09 & 74,69 \\
\hline
\end{tabular}

\subsubsection{Sensor berjumlah 200 Node}

Pada pengujian ini kami menguji 200 node sensor, hasil pengujian menunjukkan rata-rata penggunaan energi per round yang paling hemat atau efisien adalah menggunakan 4 klaster (C4) dan menggunakan 5 klaster (C5) yakni 0,38 joule dan 0,37 joule. Pada Tabel 6 menunjukan juga bahwa $\mathrm{C} 1$ atau 1 klaster dengan rata-rata data per round atau ADR (average data received) berjumlah 152,62 bytes tetapi penggunaan rata-rata energi perjoule atau AED besar yakni 1,93 joule. Penggunaan energi setelah $\mathrm{C} 1$ atau 1 klaster adalah menggunakan 3 klaster (C3 ) sebesar 102,91 bytes. Untuk menerapkan network lifetime pada sensor berjumlah 200 node dengan menganalisis energi yang paling sedikit dan data yang terkirim paling banyak adalah dengan menerapkan $\mathrm{C} 3$ dan $\mathrm{C} 4$.

Tabel 6 Total Energi dan Total Data yang menggunakan 200 node

\begin{tabular}{|lrrrrr|}
\hline $\begin{array}{l}\text { 200 } \\
\text { Nodes Round }\end{array}$ & $\begin{array}{c}\text { Total } \\
\text { Energi }\end{array}$ & $\begin{array}{c}\text { Tota } \\
\text { Data }\end{array}$ & $\begin{array}{c}\text { AED per } \\
\text { Round }\end{array}$ & $\begin{array}{c}\text { ADR per } \\
\text { Round }\end{array}$ \\
\hline C1 & 207 & 400 & 31594 & 1,93 & 152,62 \\
C2 & 448,6 & 399,99 & 43859 & 0,89 & 97,76 \\
C3 & 903,5 & 399,86 & 92986 & 0,44 & 102,91 \\
C4 & 1042,1 & 399,87 & 100928 & 0,38 & 96,85 \\
C5 & 1062,1 & 399,84 & 57005 & 0,37 & 53,67 \\
C6 & 624,8 & 399,35 & 55261 & 0,63 & 88,44 \\
C7 & 566,3 & 398,16 & 50452 & 0,70 & 89,09 \\
\hline
\end{tabular}

20 Muhammad Hibrian

\begin{tabular}{|lrrrrr|}
\hline C8 & 182,7 & 399,811 & 12343 & 2,188 & 67,55 \\
C9 & 517,6 & 398,37 & 39313 & 0,76 & 75,95 \\
C10 & 148,1 & 395,26 & 10498 & 2,66 & 70,88 \\
\hline
\end{tabular}

\section{KESIMPULAN}

Menerapkan teknik clustering atau Protokol LEACH adalah meningkatkan network lifetime yang ada pada jaringan wiress sensor network dimana penentuan klaster digunakan untuk mengetahui banyaknya data lebih banyak terkirim serta dengan menggunakan rata-rata penggunaan energi per round yang terkirim ke base station adalah minim. Besarnya jumlah klaster sangat berpengaruh terhadap banyaknya node wireless sensor network tetapi semakin besar jumlah klaster tidak memperoleh network lifetime yang lebih optimal, hal ini dapat dilihat pada skenario 1 sampai skenario 5 yang telah di lakukan seperti pada skenario 2 dengan node sebanyak 50 node menunjukkan bahwa AED (average energy dissipated) atau energi rata-rata yang dilewati setiap round paling optimal adalah klaster 2 yakni 0.2781 Joule dan yang menunjukan ADR (average data received) atau data yang terkirim atau diperoleh adalah klaster 2 juga dengan 107,4178 bytes dibandingkan dengan klaster 10 yang mendapatkan rata-rata penggunakaan energi sebesar 1,0280 joule dan memperoleh data yang terkirim hanya sebesar 30,3205 bytes. Untuk penelitian selanjutnya perlu mempertimbangkan hambatan atau gangguan $\mathrm{CH}$ mempengaruhi kinerja LEACH sehingga perlu adanya kriteria atau syarat menentukan node mana yang harus dijadikan $\mathrm{CH}$.

\section{REFERENSI}

[1] Firdaus, Wireless Sensor Network, Teori dan Aplikasinya. Graha Ilmu : Yogyakarta; 2014.

[2] Laukkarinen, T. (2017). Computer Engineering teaching. Retrieved from TIE-52106 Wireless Sensor Networks and Applications: www.tkt.cs.tut.

[3] Listyanti Dewi Astuti, Peningkatan Network Lifetime pada Wireless Sensor Network dengan Menggunakan Clustered Shortest Geopath Routing (C-SGP), Tesis; 2017.

[4] Heinzelman W, Chandrakasan A, Balakrishnan H, Energy efficient communication protocol for wireless microsensor networks. Di dalam: Annual Hawaii International Conference; System Sciences 2000. hlm 1-10.; 2000.

[5] Tian, D., \& Georganas, N. D. (2003). Energy efficient routing with guaranteed delivery in wireless sensor networks. IEEE Wireless Communications and Networking.

[6] Heinzelman W, Chandrakasan A, Balakrishnan H, An application-specific protocol architecture for wireless microsensor networks, IEEE Transactions on Wireless Communications. 1(4):660-670; 2002

[7] M. Permana, Analisa Algoritma LEACH Pada Jaringan Sensor Nirkabel, Proceeding Seminar Tugas Akhir Jurusan Teknik Elektro FTI-ITS; 2012.

[8] Hikmah Diarapat, Kinerja Dan Konsumsi Daya Protokol Routing Leach Pada Topologi Jaringan Sensor Nirkabel Berbasis Klaster. Skripsi; 2016.

[9] Thein MCM, Thein T, An energy efficient cluster-head selection for wireless sensor networks, Di dalam: Inteligent 
Systems, Modelling, and Simulation (ISMS); IEEE. hlm 287-291; 2010

[10] Wang B, Shen C, Li J, Study and improvement on LEACH protocol in WSNs, Di dalam: Automatic Control and Artificial Intelligence (ACAI); 2012 Mar 3-5; Xiamen, Cina. IEEE. hlm 1941-1943; 2012

[11] Zhang F, Wang Q, A probability optimize clustering routing algorithm for WSNs, Di dalam: Electronics Computer Technology (ICECT); IEEE. hlm 348-352; 2011

[12] Kodali RK, Aravapalli NK,Multi-level LEACH protocol model using ns-3, Di dalam: Advance Computing Conference (IACC). 2014 Feb 21-22; Gurgaon, India. IEEE International. hlm 375-380; 2014

[13] Paul AK, Sato T, Effective data gathering and energy efficient communication protocol in wireless sensor network. Di dalam: Wireless Personal Multimedia Communications (WPMC); IEEE. hlm 1-5; 2011. 